\title{
Mutu Sediaan Racikan Puyer di Kecamatan Ciputat Timur
}

\author{
Ofa Suzanti Betha, Yardi*, Yetika Alvionita, Zilhadia, Barita Juliano Siregar \\ ProgramStudi Farmasi, UIN Syarif Hidayatullah, Jakarta, Tangerang Selatan 15419, Indonesia \\ Corresponding author: yardi@uinjkt.ac.id
}

Diterima:2 Oktober 2019; Disetujui: 9 November 2019

\begin{abstract}
Drug compounding is one of the pharmaceutical services that are the responsibility of a pharmacist at a pharmacy and other pharmaceutical service facilities. The compounding process is including quality, safe and effective preparations. Drug compounding preparations must be guaranteed quality and safety. In Indonesia, there are no procedures and quality standards for compounding. The aim of this study was to evaluate the quality of powder products from pharmacy concoctions in the Kecamatan Ciputat Timur sub-district, namely uniformity of preparations. As many as 8 dispensingserving pharmacies in Kecamatan Ciputat Timur were taken as samples using the total sampling method. Weight variation and content uniformity were measured by using analytical balance and UV-Vis Spectrophotometer. The result of this research was all the samples gave under the standard of weight variation and content uniformity according to Farmakope Indonesia $\mathrm{V}$.
\end{abstract}

Keywords: Content uniformity, pharmacy, powder medicine, weight variation

Abstrak: Peracikan obat merupakan salah satu dari bentuk pelayanan kefarmasian yang menjadi tanggung jawab seorang apoteker di apotek dan sarana pelayanan kefarmasian lainnya. Proses peracikan yang baik akan menghasilkan sediaan yang bermutu, aman dan efektif. Sediaan obat termasuk sediaan hasil peracikan harus terjamin mutu dan keamanannya. Di Indonesia khususnya belum terdapat prosedur dan standar mutu sediaan racikan.Penelitian ini bertujuan melakukan evaluasi mutu puyer hasil racikan apotek di kecamatan Ciputat yaitu keseragaman sediaan. Sediaan puyer disampling dari semua apotek (8 apotek) yang terdapat di wilayah kecamatan Ciputat Timur. Analisa yang dilakukan adalah keragaman bobot dan keseragaman kandungan. Penetapan keragaman bobot dilakukan menggunakan timbangan analitik dan keseragaman kandungan menggunakan Spektrofotometer UV-Vis. Hasil dari penelitian ini menunjukkan bahwa, sediaan racikan puyer dari 8 apotek di kecamatan Ciputat Timur tidak memenuhi uji keragamanan bobot dan keseragaman kandungan menurut Farmakope Indonesia V.

Kata kunci: Apotek, keragaman bobot, keseragaman kandungan, puyer, racikan puyer.

\section{PENDAHULUAN}

Sediaan obat dapat disiapkan dengan cara diracik (compounding) maupun dibuat dalam proses manufaktur (manufacturing) oleh industri farmasi. Baik obat hasil peracikan maupun manufaktur harus memiliki mutu yang terstandar dan aman digunakan oleh pasien (Allen, 208; Gudeman, dkk, 2013). Di Indonesia, proses manufaktur obat di industri telah memiliki aturan standar yaitu CPOB 2018. Adapun proses peracikan belum memiliki prosedur terstandar seperti halnya CPOB (BPOM, 2018). Resep racikan bentuk sediaan padat seperti serbuk dan kapsul merupakan bentuk sediaan yang paling sering ditulis. Permasalahan yang sering timbul $(71,5 \%)$ adalah penggerusan berbagai bentuk sediaan tablet (Wiedyaningsih dan oetari, 2004).

Hasil penelitian terhadap puyer di sejumlah apotek di kota Depok pada 2010 menunjukkan bahwa hanya ada 1 racikan dari 32 sampel racikan puyer yang memenuhi persyaratan uji keragaman bobot seperti yang tertera pada Farmakope Indonesia IV (Mayuntari, 2010). Pengujian keseragaman bobot yang dilakukan terhadap racikan puyer dari apotek yang ada di kota Jambi menunjukkan bahwa $81,25 \%$ dari racikan puyer apotek telah memenuhi persyaratan keragaman bobot menurut Farmakope 
Indonesia III (Helni, 2014).

Persentase peresepan sediaan racikan untuk pasien pediatrik yang dilayani pada bagian rawat jalan anak di rumah sakit relatif tinggi yaitu sebesar $88,85 \%$ (Widyaswari dan Wiedyaningsih, 2012) sedangkan peresepan sediaan racikan pada pasien pediatrik dalam pelayanan rawat inap adalah sebesar $73 \%$. Jenis sediaan racikan yang lebih dominan adalah bentuk sediaan puyer dosis terbagi (pulveres). Hal lain yang perlu dicermati adalah terdapat hubungan antara pola peresepan racikan terhadap umur pasien pediatrik. Pasien pediatrik dalam kelompok $\leq 6$ tahun berpotensi memperoleh peresepan racikan sebesar 14 kali lebih besar dibandingkan dengan pasien pediatrik berusia $\geq 6$ tahun. Hal ini semakin menguatkan bahwa sangat pentingnya pengawasan kualitas sediaan racikan yang merupakan tanggung jawab seorang apoteker. Menurut data yang diperoleh dari dinas kesehatan Tangerang Selatan pada tahun 2018 terdapat sebanyak 38 apotek di kecamatan Ciputat Timur. Data terkait penelitian mutu sediaan racikan puyer di kecamatan Ciputat Timur belum tersedia sehingga perlu dilakukan penelitian terkait hal ini

\section{BAHAN DAN METODE}

\subsection{Alat dan Bahan}

Alat yang digunakan dalam penelitian adalah spektrofotometri UV-vis (Hitachi U-2910). Adapun bahan yang digunakan di antaranya, standar yang didapatkan dari BPOM, metanol p.a(Merck). Resep racikan dibuat berupa racikan puyer parasetamol $250 \mathrm{mg}$ sebanyak 30 bungkus yang diperoleh dengan bekerja sama dengan dokter praktek berizin resmi.

\subsection{Metode Penelitian}

Penelitian yang dilakukan ini adalah penelitian deskripsi (Notoatmojo, 2012) di mana pengumpulan data berupa mutu sediaan racikan didapatkan dengan cara menebus resep racikan langsung ke apotek di kecamatan Ciputat Timur, Tangerang Selatan. Berdasarkan data yang diperoleh dari dinas kesehatan pada tahun 2018 terdapat jumlah populasi 43 apotek di daerah Kecamatan akan tetapi hanya 31 apotek yang masih beroperasi di daerah Kecamatan Ciputat Timur dan hanya terdapat 8 apotek yang melayani resep racikan puyer dan memenuhi kriteria inklusi dan ekslusi. Maka jumlah sampel yang digunakan adalah sebanyak 8 apotek.

Jenis data yang digunakan yaitu data primer yang diperoleh atau dikumpulkan langsung di lapangan. Data primer berupa penebusan obat racikan puyer dengan resep dokter dan pengisian kuesioner oleh apoteker penanggung jawab apotek dan atau tenaga teknis kefarmasian yang melakukan pengisian kuestioner. Selanjutnya setiap unit racikan puyer dianalisis keragaman bobot dengan cara Sediaan puyer yang telah dibeli dari beberapa apotek yang telah di tetapkan ditimbang satu persatu menggunakan neraca analitik dilakukan secara triplo, kemudian dicatat dan dimasukkan ke tabel. Setelah itu dilakukan penghitungan rata-rata bobot puyer dari setiap apotek dan mencatatnya kemudian dibandingan hasilnya dengan persyaratan yang tertera dalam farmakope.

Puyer yang ditimbang kemudian dihitung bobot persennya dengan cara sebagai berikut:

Bobot dalam persen $=\frac{\text { bobot puyer }}{\text { bobot rata-rata puyer }} \times 100 \%$ Selanjutnya dihitung persen simpangan baku relatif (\%SBR) dengan cara:

$\%$ SBR $=\frac{\sqrt{\frac{\left(\sum(x-x) \Omega\right)}{n-1}}}{x} \times 100 \%$ 
Menurut FIV hasil pengujian keragaman bobot terhadap 30 puyer dinyatakan memenuhi persyaratan jika nilai penerimaan kurang dari atau sama dengan L1\% dan tidak ada satupun sediaan kurang dari [1-(0,01)(L2)]M atau tidak ada satupun sediaan lebih dari $[1+(0,01)(\mathrm{L} 2)] \mathrm{M}$ seperti tertera pada perhitungan nilai penerimaan dalam keragaman bobot. Kecuali dinyatakan lain L1 adalah 15,0 dan L2 adalah 25,0. Pengujian keseragaman kandungan dilakukan terhadap sampel jika racikan puyer tersebut tidak memenuhi persyaratan yang ditetapkan oleh FI V. Sebelumnya penetapan kadar dalam puyer racikan dilakukan menggunakan metode spektrofotometer UV-vis (Tulandi, Dewi and Lolo, 2015).

Analisis keragaman bobot dan keseragaman kandungan dilakukan dengan cara seperti yang ditetapkan oleh Farmakope Indonesia V (Depkes, 2015). Untuk melengkapi data penelitian dilakukan wawancara dan pengisian questioner pada waktu yang berbeda terhadap personil di apotek yang merupakan tempat peracikan puyer yang diuji. Data yang diamati dari kuisioner di antaranya adalah harga, jumlah pelayanan resep racikan, peracikan, jumlah apoteker, jumlah tenaga teknis kefarmasian, alat yang digunakan untuk peracikan, pembungkus sediaan puyer, kemasan (Allen, 2008).

\section{HASIL DAN DISKUSI}

\subsection{Hasil Pengujian Keragaman Bobot}

Hasil pemeriksaan mutu sediaan puyer racikan yang mengandung $250 \mathrm{mg}$ setiap bungkusnya didapatkan dari 8 apotek yang dapat menerima resep racikan. Hasil pemeriksaan mutu keragaman bobot 10 bungkus racikan sampel dari apotek CT01, СT02, СT03, СT04 dan СT05, СT06, СT07, CT08 dapat dilihat pada Tabel 1 - 8. Dari perhitungan diperoleh bobot rata-rata sampel puyer apotek CT01 adalah 304,04 mg dengan simpangan baku sebesar 15,42 mg dan simpangan baku relatif sebesar $5,71 \%$.

Dari hasil ini didapatkan nilai penerimaan sampel apotek CT01 adalah 37,01\%. Hasil perhitungan bobot rata-rata sampel puyer dari apotek CT02, apotek CT03, apotek CT04, apotek CT05, apotek CT06, apotek CT07 dan apotek CT08 secara berurutan adalah 275,$57 ; 300,60 ; 279,04 ; 338,12$ ; 264,52 ; 271,71; 269,14 mg. Dari perhitungan selanjutnya seperti yang digunakan pada apotek CT01 didapatkan nilai penerimaan ke tujuh apotek tersebut secara berurutan adalah $(56,16)$; $(31,55)$; $(37,93) ;(25,03) ;(47,67) ;(48,94) ;(37,91)$.

Tabel 1. Hasil uji mutu bobot dari 10 unit pertama puyer racikan apotek CT01.

\begin{tabular}{cccc}
\hline No Sampel & Bobot Puyer $(\mathbf{m g})$ & \% bobot & $\left(\mathbf{x}-\mathbf{x}^{\prime}\right)^{\wedge} \mathbf{2}$ \\
\hline 1 & 381,97 & 125,63 & 656,78 \\
2 & 309,23 & 101,71 & 2,91 \\
3 & 280,93 & 92,40 & 57,79 \\
4 & 235,60 & 77,49 & 506,79 \\
5 & 281,33 & 92,53 & 55,81 \\
6 & 262,90 & 86,47 & 183,14 \\
7 & 284,80 & 93,67 & 40,07 \\
8 & 375,63 & 123,55 & 554,35 \\
9 & 330,83 & 108,81 & 77,62 \\
10 & 297,23 & 97,76 & 5,02 \\
\hline
\end{tabular}

Tabel 2. Hasil uji mutu bobot dari 10 unit pertama puyer racikan apotek $\mathrm{CT} 02$

\begin{tabular}{cccc}
\hline No Sampel & Bobot Puyer $(\mathbf{m g})$ & \% bobot & $\left(\mathbf{x}-\mathbf{x}^{\prime}\right)^{\wedge} \mathbf{2}$ \\
\hline 1 & 286,87 & 104,10 & 16,81 \\
2 & 319,03 & 115,77 & 248,80 \\
3 & 188,43 & 68,38 & 999,81 \\
4 & 206,97 & 75,11 & 619,72 \\
5 & 199,00 & 72,21 & 772,02 \\
6 & 286,10 & 103,82 & 14,611 \\
7 & 385,10 & 139,75 & 1579,84 \\
8 & 330,70 & 120,01 & 400,29 \\
9 & 244,37 & 88,68 & 128,19 \\
10 & 309,10 & 112,17 & 148,08 \\
\hline
\end{tabular}

Menurut FI V sampel sediaan puyer dinyatakan memenuhi syarat keragaman bobot jika memiliki nilai penerimaan 10 unit sediaan puyer pertama 
tidak kurang atau sama dengan L1\%. Jika nilai penerimaan lebih besar dari L1\%, maka dilakukan pengujian pada 20 unit sediaan tambahan dan dihitung nilai penerimaannya. Dimana L1 adalah nilai penerimaan maksimum yang diperbolehkan. Nilai L1 adalah 15,0 kecuali dinyatakan lain pada masing-masing monografi (Anonim, 2014). Berdasarkan hal ini disimpulkan bahwa untuk 10 unit pertama sampel dari setiap apotek dinyatakan tidak memenuhi syarat keragaman bobot.

Tabel 3. Hasil uji mutu bobot dari 10 unit pertama puyer racikan apotek CT03.

\begin{tabular}{cccc}
\hline No Sampel Bobot Puyer $(\mathbf{m g})$ & \% bobot & $\left(\mathbf{x}-\mathbf{x}^{\prime}\right)^{\wedge} \mathbf{2}$ \\
\hline 1 & 280,13 & 93,19 & 46,37 \\
2 & 271,50 & 90,32 & 93,74 \\
3 & 396,70 & 131,97 & 1021,95 \\
4 & 301,77 & 100,39 & 0,15 \\
5 & 292,27 & 97,23 & 7,69 \\
6 & 244,27 & 81,26 & 351,23 \\
7 & 310,67 & 103,35 & 11,20 \\
8 & 294,60 & 98,00 & 3,99 \\
9 & 300,60 & 99,99 & 1,21 \\
10 & 313,53 & 104,30 & 18,50 \\
\hline
\end{tabular}

Tabel 4. Hasil uji mutu bobot dari 10 unit pertama puyer racikan apotek CT04.

\begin{tabular}{cccc}
\hline No Sampel & Bobot Puyer $(\mathbf{m g})$ & \% bobot & $\left(\mathbf{x}-\mathbf{x}^{`}\right)^{\wedge} \mathbf{2}$ \\
\hline 1 & 265,37 & 95,10 & 24,02 \\
2 & 265,47 & 95,14 & 23,67 \\
3 & 319,53 & 114,51 & 210,55 \\
4 & 253,00 & 90,67 & 87,11 \\
5 & 218,43 & 78,28 & 471,79 \\
6 & 212,63 & 76,20 & 566,40 \\
7 & 315,57 & 113,09 & 171,32 \\
8 & 307,83 & 110,32 & 106,45 \\
9 & 286,30 & 102,60 & 6,76 \\
10 & 346,30 & 124,10 & 580,94 \\
\hline
\end{tabular}

Setelah dilakukan pengujian keragaman bobot terhadap 30 unit sampel puyer dari 8 apotek tersebut, maka tidak ada satupun yang memenuhi persyaratan selanjutnya seperti yang tertera pada FI $\mathrm{V}$ yaitu : hasil penimbangan terhadap 30 puyer dinyatakan memenuhi persyaratan jika nilai penerimaan kurang dari atau sama dengan L1\% dan tidak ada satupun sediaan kurang dari [1-
$(0,01)(\mathrm{L} 2)] \mathrm{M}$ atau tidak ada satupun sediaan lebih dari $[1+(0,01)(\mathrm{L} 2)] \mathrm{M}$ seperti tertera pada perhitungan nilai penerimaan dalam keragaman bobot. Kecuali dinyatakan lain L1 adalah 15,0 dan L2 adalah 25,0. (Anonim, 2014). Nilai penerimaan sampel dari 8 apotek dapat dilihat pada Tabel 9 di mana tidak satupun sampel puyer yang memenuhi persyaratan yang tertera pada FI V.

Tabel 5. Hasil uji mutu bobot dari 10 unit pertama puyer racikan apotek CT05.

\begin{tabular}{ccrr}
\hline No Sampel & Bobot Puyer $(\mathrm{mg})$ & \% bobot & $\left(\mathrm{x}-\mathrm{x}^{\prime}\right)^{\wedge} 2$ \\
\hline $\mathbf{1}$ & 341,93 & 101,13 & 1,27 \\
$\mathbf{2}$ & 371,53 & 109,88 & 97,66 \\
$\mathbf{3}$ & 307,73 & 91,01 & 80,76 \\
$\mathbf{4}$ & 366,27 & 108,33 & 69,30 \\
$\mathbf{5}$ & 303,77 & 89,84 & 103,23 \\
$\mathbf{6}$ & 372,80 & 110,26 & 105,20 \\
$\mathbf{7}$ & 301,30 & 89,11 & 118,59 \\
$\mathbf{8}$ & 317,37 & 93,86 & 37,67 \\
$\mathbf{9}$ & 393,57 & 116,40 & 268,91 \\
$\mathbf{1 0}$ & 304,93 & 90,19 & 96,34 \\
\hline
\end{tabular}

Tabel 6. Hasil uji mutu bobot dari 10 unit pertama puyer racikan apotek CT06.

\begin{tabular}{cccc}
\hline No Sampel & Bobot Puyer $(\mathbf{m g})$ & \% bobot & $\left(\mathbf{x}-\mathbf{x}^{\prime}\right)^{\wedge} \mathbf{2}$ \\
\hline 1 & 206,93 & 78,23 & 473,99 \\
2 & 232,40 & 87,86 & 147,47 \\
3 & 280,87 & 106,18 & 38,17 \\
4 & 219,53 & 82,99 & 289,27 \\
5 & 254,53 & 96,22 & 14,26 \\
6 & 187,40 & 70,84 & 850,05 \\
7 & 315,30 & 119,20 & 368,47 \\
8 & 306,90 & 116,02 & 256,64 \\
9 & 293,50 & 110,95 & 119,99 \\
10 & 347,87 & 131,51 & 992,69 \\
\hline
\end{tabular}

Tabel 7. Hasil uji mutu bobot dari 10 unit pertama puyer racikan apotek CT07.

\begin{tabular}{cccc}
\hline No Sampel & Bobot Puyer $(\mathbf{m g})$ & \% bobot & $\left(\mathbf{x}-\mathbf{x}^{\prime}\right)^{\wedge} \mathbf{2}$ \\
\hline 1 & 267,70 & 98,45 & 2,40 \\
2 & 210,70 & 77,49 & 506,79 \\
3 & 344,70 & 126,77 & 716,55 \\
4 & 206,10 & 75,80 & 585,82 \\
5 & 251,00 & 92,31 & 59,15 \\
6 & 232,20 & 85,40 & 213,31 \\
7 & 307,30 & 113,01 & 169,36 \\
8 & 363,83 & 133,81 & 1142,77 \\
9 & 303,30 & 111,54 & 133,24 \\
10 & 232,30 & 85,43 & 212,24 \\
\hline
\end{tabular}


Sesuai persyaratan yang ditetapkan pada FI V, maka selanjutnya dilakukan uji keseragaman kandungan terhadap puyer racikan semua apotek. Sebelumnya dilakukan validasi metode analisis parasetamol menggunakan metode analisis dengan alat spektrofotometer (Tulandi, 2015).

Tabel 8. Hasil uji mutu bobot dari 10 unit pertama puyer racikan apotek CT08.

\begin{tabular}{cccc}
\hline $\begin{array}{c}\text { No } \\
\text { Sampel }\end{array}$ & Bobot Puyer $(\mathbf{m g})$ & \% bobot & $\left(\mathbf{x}-\mathbf{x}^{\prime}\right)^{\wedge} \mathbf{2}$ \\
\hline 1 & 210,20 & 78,10 & 479,58 \\
2 & 253,50 & 94,19 & 33,77 \\
3 & 309,10 & 114,85 & 220,44 \\
4 & 280,80 & 104,33 & 18,77 \\
5 & 207,90 & 77,25 & 517,74 \\
6 & 243,20 & 90,36 & 92,89 \\
7 & 334,60 & 124,32 & 591,56 \\
8 & 310,30 & 115,29 & 233,88 \\
9 & 285,20 & 105,97 & 35,61 \\
10 & 256,60 & 95,34 & 21,71 \\
\hline
\end{tabular}

Tabel 9 Nilai penerimaan hasil uji mutu 30 unit puyer racikan 8 apotek sampel.

\begin{tabular}{lccc}
\hline Apotek & $\begin{array}{c}\text { Bobot rata-rata Simpangan baku } \\
(\mathrm{mg})\end{array}$ & $\begin{array}{c}\text { NP } \\
(\mathrm{mg})\end{array}$ & \\
\hline CT01 & 311,16 & 15,28 & 30,56 \\
CT02 & 282,59 & 19,28 & 38,55 \\
CT03 & 302,44 & 16,35 & 32,70 \\
CT04 & 289,58 & 19,97 & 39,64 \\
CT05 & 341,75 & 13,85 & 27,70 \\
CT06 & 279,33 & 20,45 & 40,89 \\
CT07 & 296,58 & 22,62 & 45,24 \\
CT08 & 282,73 & 14,71 & 29,41 \\
\hline
\end{tabular}

\subsection{Hasil Pengujian Keseragaman Kandungan}

Penetapan kadar parasetamol dalam puyer racikan dilakukan dengan spektrofotometer UV-vis dengan sebelumnya melakukan penentuan panjang gelombang maksimum dan hasilnya didapatkan pada $244 \mathrm{~nm}$, (Gambar 1 dan 2) menggunakan pelarut metanol-air (1:3). Kurva kalibrasi parasetamol racikan dan parasetamol BPFI menghasil garis lurus dengan koefisien korelasi secara berurutan 0,999 dan 0,998 dengan persamaan regresi linear $\mathrm{y}=0,0615 \mathrm{x}+0,0001$ untuk parasetamol (Panadol) dan $\mathrm{y}=0,067 \mathrm{x}+$ 0,0004 untuk parasetamol BPFI. Hasil pengujian batas deteksi (LOD) sebesar 0,1655 ppm dan batas kuantitasi (LOQ) sebesar 0,5516 ppm untuk pengujian parasetamol BPFI dan 0,1055 ppm dan 0,3517 ppm untuk parasetamol sampel. Pengujian presisi dan akurasi dilakukan pada larutan baku yaitu $80 \%$, $100 \%$ dan $120 \%$ dengan hasil seperti pada Tabel 10.

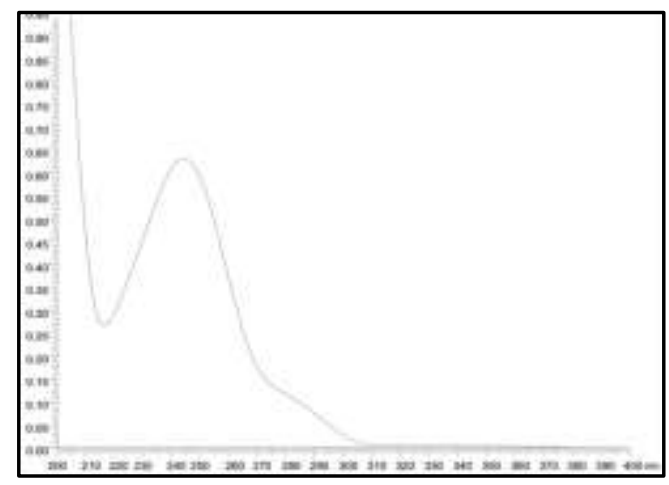

Gambar 1. Spektrum UV parasetamol racikan konsentrasi $10 \mathrm{ppm}$

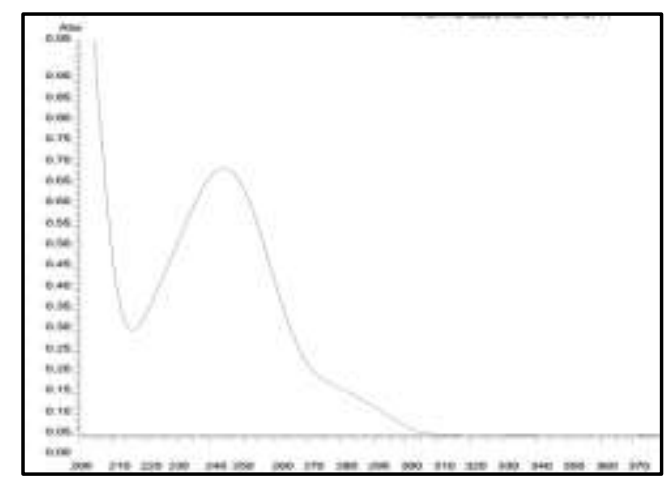

Gambar 2. Spektrum UV parasetamol BPFI konsentrasi $10 \mathrm{ppm}$

Tabel 10. Hasil pengujian akurasi presisi

\begin{tabular}{cccc}
\hline Sampel & $\begin{array}{c}\text { Konsentrasi } \\
\text { pengujian }\end{array}$ & \%UPK & SD \\
\hline $80 \%$ & 9,428 & $98,48 \pm 0,76$ & 0,76 \\
& 9,364 & $95,58 \pm 1,02$ & 1,02 \\
& 9,410 & $99,21 \pm 0,80$ & 0,80 \\
$100 \%$ & 11,784 & $96,65 \pm 1,09$ & 1,12 \\
& 11,706 & $96,73 \pm 0,99$ & 1,02 \\
& 11,764 & $100,18 \pm 1,02$ & 1,02 \\
$120 \%$ & 14,142 & $96,25 \pm 0,83$ & 0,87 \\
& 14,046 & $91,88 \pm 0,20$ & 0,22 \\
& 14,116 & $94,16 \pm 0,79$ & 0,84 \\
\hline
\end{tabular}

Dari pengujian kadar terhadap 10 unit puyer dari 
masing-masing apotek didapatkan hasil seperti pada Tabel 10. Dari 10 unit yang diukur sampel dari apotek CT01 hanya sebanyak 5 unit yang memenuhi syarat sesuai FI V, sedangkan apotek CT02 - CT08 secara berurutan terdapat 1, 8, 3, 5, 3, 2, 4 unit puyer yang memenuhi persyaratan, hal ini berdasarkan pada pernyataan monografi parasetamol FI V bahwa kadar zat aktif parasetamol dalam suatu sediaan berada pada rentang 90 - $110 \%$ dari kadar yang tertera pada etiket, yang berarti kadar parasetamol yang memenuhi syarat ada pada rentang 225 - $275 \mathrm{mg}$. Hasil uji keseragaman kandungan terhadap 10 unit sampel puyer racikan dari 8 apotek di kecamatan Ciputat Timur menunjukkan hasil bahwa tidak ada satupun sediaan racikan puyer dari apotek-apotek tsb yang memenuhi persyaratan keseragaman kandungan sesuai persyaratan yang ditetapkan oleh FI V. Dari data wawancara dan kuesioner diketahui bahwa dari 8 apotek di wilayah Kecamatan Ciputat Timur, sebagian besar apotek hanya memiliki 1 apoteker yang bertugas selama masa operasionalnya yaitu 6 apotek $(62,5 \%)$ dan sisanya memiliki 2 apoteker yang bertugas pada masa operasional apotek (37,5\%). Dari 8 apotek tersebut terdapat 3 apotek $(37,5 \%)$ yang memiliki 2 orang tenaga teknis kefarmasian, 2 apotek (25\%) yang memiliki 3 orang tenaga teknis kefarmasian, dan 1 apotek yang memiliki 4 orang tenaga teknis kefarmasian serta 2 apotek yang memiliki lebih dari 4 orang tenaga teknis kefarmasian. adalah 5 apotek $(62,5 \%)$ peracikannya dilakukan oleh tenaga teknis kefarmasian, 2 apotek peracikan dilakukan oleh apoteker tetapi lebih sering oleh tenaga teknis kefarmasiansisanya 1 apotek lebih sering apoteker yang melakukan peracikan. Dengan lebih dari $50 \%$ personil yang meracik adalah apoteker sendiri ternyata dari hasil analisis keragaman bobot dan keseragaman kandungan belum dihasilkan puyer racikan yang memenuhi persyaratan menurut FI V. Dari hal ini dapat dilihat bahwa personil peracikan bukan faktor utama yang memberikan pengaruh terhadap mutu racikan.

Peralatan yang digunakan dalam peracikan di apotek relatif bervariasi. Didapatkan data bahwa alat yang digunakan untuk melakukan peracikan berupa blender digunakan oleh 4 apotek $(50,0 \%)$ dan yang menggunakan lumpang alu sebanyak 4 apotek (50,0\%). Penggunaan alat dapat berpengaruh terhadap kualitas dan kecepatan pelayanan obat puyer, blender relatif banyak digunakan untuk kepentingan dapat mempermudah pekerjaan menggerus puyer, dan menghemat tenaga dan waktu (USP, 2014). Berbeda dari hasil penelitian ini belum dapat dilihat pengaruh alat-alat yang digunakan dalam proses peracikan terhadap mutu puyer racikan karena semua sampel yang diambil dari lapangan tidak ada yang memenuhi persyaratan mutu yang dipersyaratkan oleh FI V.

Tabel 11. Hasil penetapan kadar 10 unit sediaan puyer racikan dari 8 apotek

\begin{tabular}{|c|c|c|c|c|c|c|c|}
\hline \multicolumn{8}{|c|}{ Kadar Parasetamol dalam 10 unit puyer apotek (mg) } \\
\hline CT & CT & CT & CT & $\mathbf{C T}$ & $\overline{\mathbf{C T}}$ & $\mathbf{C T}$ & CT \\
\hline 01 & 02 & 03 & 04 & 05 & 06 & 07 & 08 \\
\hline 357,64 & 267,40 & 243,82 & 251,68 & 284,70 & 184,47 & 219,16 & 199,11 \\
\hline 286,37 & 295,00 & 238,13 & 252,22 & 300,73 & 210,49 & 174,99 & 211,30 \\
\hline 256,56 & 173,63 & 351,14 & 312,11 & 248,70 & 248,70 & 298,02 & 252,76 \\
\hline 212,11 & 184,20 & 268,21 & 241,92 & 296,67 & 198,30 & 161,44 & 249,51 \\
\hline 258,46 & 188,54 & 238,94 & 211,57 & 235,15 & 231,62 & 205,61 & 178,78 \\
\hline 239,76 & 279,32 & 208,59 & 197,75 & 311,30 & 164,15 & 189,08 & 216,99 \\
\hline 260,08 & 374,17 & 264,96 & 304,26 & 232,44 & 281,76 & 260,35 & 287,72 \\
\hline 350,87 & 314,55 & 253,58 & 296,13 & 257,64 & 278,78 & 321,87 & 286,10 \\
\hline 298,84 & 224,31 & 256,02 & 276,07 & 325,94 & 273,36 & 255,47 & 260,08 \\
\hline 272,55 & 280,95 & 270,65 & 328,65 & 251,95 & 321,06 & 182,03 & 231,63 \\
\hline
\end{tabular}




\section{KESIMPULAN}

Hasil uji mutu bobot dan kadar sampel racikan puyer yang berasal dari 8 apotek di kecamatan Ciputat Timur belum ada yang memenuhi persyaratan keseragaman sediaan sebagaimana yang ditetapkan dalam Farmakope Indonesia edisi V.

\section{DAFTAR PUSTAKA}

Allen, L. V. (2008) The art, Science, and Technology of Pharmaceutical Compounding. Third Edit. American Pharmacists Association (APhA), doi: 10.1111/1539-6975.00054.

Ansel, H.C. (2014). Pharmaceutical Dosage Forms and Drug Delivery Systems, $10^{\text {th }}$.Lippincott William and WIllkins.

BPS Kota Tanggerang Selatan. (2015). Kota Tangerang Selatan dalam Angka 2015, Badan Pusat Statistik kota Tangerang Selatan.

BPS. (2017). Katalog BPS: Kecamatan Ciputat Dalam Angka 2017. Badan Pusat Statistik kota Tanggerang Selatan.

BPS. (2017). Katalog BPS: Kecamatan Ciputat Timur Dalam Angka (2017). Badan Pusat Statistik kota Tanggerang Selatan.

Darsono.(2002). Diagnosis dan Terapi Intoksikasi Salisilat dan.Bandung: Universitas Kristes Maranatha.

Departemen Kesehatan. (1979). Farmakope Indonesia edisi ke 3. Jakarta: Direktorat Jendral Pengawasan Obat dan Makanan Departemen Kesehatan RI.

Departemen Kesehatan. (1995). Farmakope Indonesia, edisi ke 4. Jakarta: Direktorat jendral pengawasan obat dan makanan departemen RI.

Departemen Kesehatan. (2000). Informatorium Obat Nasional Indonesia 2000. Jakarta: Departemen Kesehatan Republik Indonesia Direktorat Jendral Pengawasan Obat dan Makanan 2000 .

Kementrian Kesehatan RI. (2014). Farmakope Indonesia, edisi ke 5. Jakarta: Direktorat Jendral Pengawasan Obat dan Makanan Departemen RI.

Gudeman, J. et al. (2013) 'Potential risks of pharmacy compounding', Drugs in $R$ and D, 13(1), pp. 1-8. doi: 10.1007/s40268-013-0005-9.

Helni (2014). Studi Keragaman bobot Sediaan Pulveres yang dibuat Apotek di Kota Jambi.
Skripsi. Fakultas Kedokteran dan Ilmu Kesehatan Universitas Jambi Kampus Pinang Masak, Mendalo.Jambi.

Mayuntari, Ni Luh Enie. (2010). Evaluasi Mutu Sediaan Puyer Ditinjau dari Keragaman Bobot dan Faktor yang Mempengaruhinya, Skripsi.Fakultas Matematika dan Ilmu Pengetahuan Program Studi Farmasi Ekstensi.Universitas Indonesia.

Notoatmodjo, S. (2012). Metodologi Penelitian Kesehatan. PT. Rineka Cipta. Jakarta.

Kementrian Hukum dan Hak Asasi Manusia.(2009). Peraturan Pemerintah RI nomor 51 tentang Pekerjaan Kefarmasian.

Kepala BPOM. (2018). Peraturan Badan Pengawasan Obat dan Makanan RI no: HK.03.1.33.12.12.8195 Tahun (2012) tentang Penerapan Pedoman Cara Pembuatan Obat yang Baik.Kepala Badan Pengawasan Obat dan Makanan Republik Indonesia.

Peraturan Mentri Kesehatan RI. (2016). Peraturan Menteri Kesehatan Republik Indonesia Nomor \& 3 Tahun 2016 Tentang Standar Pelayanan Kefarmasian. Jakarta

Peraturan Mentri Kesehatan RI. (2017). Peraturan Menteri Kesehatan Republik Indonesia Nomor 9 Tahun 2017 tentang Apotek. Jakarta.

Riyanto. (2014). Validasi \& Verifikasi Metode Uji: Sesuai dengan ISO/IEC 17025 Laboratorium Pengujian dan Kalibrasi. Yogyakarta: Deepublish

Sastrohamidjojo, H. (1991). Spektroskopi, Liberty. Yogyakarta.

Sujarweni, V. Wiratna.(2014). Metode Penelitian, lengkap, praktis, dan mudah dipahami. Yogyakarta : pustaka baru. Press.

Tulandi, G. P., Dewi, S. and Lolo, W. A. (2015) 'Validasi Metode Analisis Untuk Penetapan Kadar Tablet Asam Mefenamat Secara Spektrofotometri', Pharmacon Jurnal Ilmiah Farmasi, 4(4), pp. 23022493.

USP.(2007). United State of Pharmacopoeia XXX.The USP Convention.Inc. Rockville. 1075.

USP.(2014). Pharmaceutical Componding Nonsteril Preparation.The USP Convention.

Wiedyaningsih, C; Oetari, RA. (2004). 'Tinjauan Terhadap Bentuk Sediaan Obat: Kajian Resep Di Apotek Kotamadya. Yogyakarta'. Majalah Farmasi Indonesia. 14(10), 201-207

Williams, Dudley H. (2013). Metode Spektroskopi Dalam Kimia Organik. alih bahasa, Lolita, July Manurung, Winny Riviani Syarief ; editor, Hafshah Nurul Afifah. Ed. 6.Jakarta : EGC

Widyaswari, R. and Wiedyaningsih, C. (2012) 
'Evaluasi Profil Peresepan Obat Racikan Dan Ketersediaan Formula Obat Untuk Anak Di Puskesmas Propinsi Diy', Majalah Farmaseutik, 8(3), pp. 227-234.: 